\title{
Ärztlicher Eros und Ethos
}

\section{Jann P. Schwarzenbach}

Dr. med., Facharzt für Allgemeinmedizin, Mitglied FMH

Die im obigen Titel umschriebene Thematik ist - von Bergdoktoren-Soaps und Schwarzwaldklinik einmal abgesehen - für uns ärztliche Realos alles andere als unproblematisch. Schon vor allen \#MeToo-Debatten ist es nämlich stets ethisch fragwürdig gewesen, im medizinischen Umfeld von Eros zu sprechen. Dieser ist in unserem beruflichen Alltag meist zur falschen Zeit am falschen Ort, und das Sprechzimmer gilt für ihn erst recht als kategorische No-Go-Area. Andererseits finden sich in der Erotik die dynamischsten und farbenfrohsten Momente, die wir in unserer oft graugetünchten Welt erleben dürfen, und so wäre es eigentlich schade oder - wie ich im letzten Abschnitt dieses

\section{In der Erotik finden sich die dynamischsten und farbenfrohsten Kräfte, die wir in unserer graugetünchten Welt erleben dürfen.}

Aufsatzes erläutern möchte - für die Patienten sogar schädlich, diese uns allen vertraute, zu stetiger Suche drängende Kraft in der Medizin ganz auszuklammern. So werde ich also versuchen, ärztlichen Ethos und Eros doch irgendwie als miteinander verbunden $\mathrm{zu}$ betrachten. Dies würde eventuell gelingen, wenn man das sprichwörtlich «ewig Weibliche» über ein konkretes Gegenüber hinaus, als allgemeine, uns zum Vorteil der Kranken anspornende Kraft, verständlich machen könnte. Im Rahmen unserer vertrauten Art zu argumentieren dürfte das allerdings schwierig sein, und so möchte ich drei berühmte Philosophen zu diesem Thema zu Wort kommen lassen.

\section{Eros als Quälgeist}

Arthur Schopenhauer (1788-1860) war ein unerbittlicher Kritiker und zynischer Kommentator aller sinnlich-erotischen Genüsse. Er sah in diesen nichts anderes als eine lustvolle Illusion, die ein alles beherrschender Weltwille dem Einzelnen nur vorgaukelt. So versetzt denn dieser Wille, dem es grundsätzlich nur um das Fortbestehen der Arten geht, die armen Individuen in eine Art von Delirium und drängt sie zu sehnsüchtig-leidendem Schmachten und mannigfachen oft lächerlichen Verrenkungen seelischer und körperlicher Art. Für irgendeine Form von Ethos ist hier kein Platz. Diesen findet Schopenhauer nur im Zusammen- hang mit persönlicher Willensverneinung und Askese, dem freiwilligen Verzicht auf alle egoistischen Bedürfnisse und individuellen Lüste. Dies soll uns dann erst frei machen für eine echte und ethisch wertvolle Anteilnahme am Mitmenschen.

\section{Ethos als existentielle Wahl}

Søren Kierkegaard (1813-1855) beschreibt in der ästhetischen, der Sinneslust frönenden Art zu leben eine mögliche, typisch menschliche Existenzform. Diese ist aber nicht nur als ein triebhaft-instinktives Dasein zu verstehen, denn der Mensch, selbst wenn er ausschliesslich seinen Sinnen gemäss lebt, denkt gleichzeitig über sein Tun und Lassen nach. Das erhöht den persönlichen Genuss über das rein Körperliche hinaus, und Kierkegaard illustriert dies an der Figur des Don Juan, der nicht primär im Vollzug seiner erotischen Begierden, sondern in deren Vorfreude schwelgt. Salopp resümiert, studiert er lange das Menü, geniesst die Vorspeisen, schlingt den Hauptgang hinunter und ist zum Nachtisch bereits verschwunden. So wird die perfekte Kunst der Verführung zu seinem ganzen Lebensinhalt. Anderseits kann die Selbstreflexion des einer leeren Sinnlichkeit ergebenen Menschen schlussendlich auch zu Lebensüberdruss und verzweifelter Einsamkeit führen. Als Ausweg aus diesem Tunnel muss der Einzelne dann selbst zu einer neuen Art von Existenz finden, und Kierkegaard nennt diese, im Gegensatz zur ästhetisch-sinnlichen, die ethische Lebensform. Sie besteht in der Übernahme verschiedener durch eigene Einsicht gewonnener Regeln und Werte. Dies ist ein Akt persönlicher Freiheit und soll die Sinnlichkeit keineswegs aufheben, sondern in vernünftige Bahnen lenken und so unser Verhältnis zum Mitmenschen zu einer echten Beziehung werden lassen: im Beruf, in der Freundschaft oder - was die Erotik betrifft auch in der Ehe.

\section{Eros als Wegweiser}

Während in Schopenhauers Philosophie Erotik und Ethik sich unversöhnlich gegenüberstehen und diese sich für Kierkegaard nur dank einer existentiellen Entscheidung vereinbaren lassen, erscheint in Platos (ca. 425-348 v. Chr.) berühmtem «Symposion» der Eros 
gar als Schlüsselfigur zu wahrem Wissen um das Gute und Richtige. Er wird da als eine Art von dämonischem Mangelwesen beschrieben, das in bedürftiger Unruhe allgemein nach Zuneigung und Schönheit Ausschau

\section{Zur Idee des absolut Schönen vermag auch der gewöhnliche Sterbliche mit Hilfe seiner visuellen Fähigkeiten vorzustossen.}

hält. Als Protagonist der sprichwörtlichen platonischen Liebe - die entgegen landläufiger Vorurteile die Körperlichkeit durchaus einschliesst - strebt Eros dabei vom sinnlich Fassbaren zu stets Abstrakterem und Höherem. So kann derjenige, der sich von ihm beflügeln lässt, imstande sein, über die physische Anmut hinaus in erweiterten Bereichen ästhetisch ansprechende Elemente zu sehen: etwa in der menschlichen Seele, in echter Freundschaft, im Staat oder im eigenen Beruf. Ziel dieser Blicksafari durch alle Erscheinungsweisen der Schönheit ist die Ansicht dieser Letzteren selbst, so wie sie, als unvergängliche Idee, an und für sich ist. Dies lässt sich nur im Rahmen von Platos Metaphysik verstehen. Die Welt der Ideen ist für ihn die Herberge der zeitlos gültigen, wahren Grundinhalte aller irdischen, dem steten Wechsel unterworfenen Erscheinungen. So ruhen in dieser Schatztruhe, um nur einige Beispiele zu nennen, analog zur Idee der Schönheit, eben auch die der Tapferkeit, der Gesundheit oder der Gerechtigkeit, deren Abbilder sich in der uns erscheinenden Welt jeweils mehr oder weniger deutlich auffinden lassen. Der Zugang zur wahren Natur der Ideen bleibt unseren fünf Sinnen aber normalerweise verwehrt und ist nach Plato allein dem philosophischen Denken vorbehalten. Zur Idee des absolut Schönen vermag aber, wie vorher beschrieben, auch der gewöhnliche Sterbliche - Eros sei Dank mit seinen visuellen Fähigkeiten vorzustossen. HansGeorg Gadamer (1900-2002) hat dies mit folgendem
Satz auf den Punkt gebracht: «Schönheit ist in der Seinsweise des Lichts.» Das heisst mit anderen Worten: Ihr innerstes Wesen ist erkennbares Leuchten. Und da für Plato die Schönheit, als Ausdruck von Verhältnismässigkeit, Harmonie und Perfektion, auch mit dem effektiv Guten zusammenhängt, kann die Begegnung mit der Idee des Schönen uns auch als Anleitung dienen, ethisch richtig zu handeln.

\section{Feu sacré}

Somit hätten wir also schliesslich, in der engen Verwandtschaft des Schönen und des Guten, das am Anfang des Aufsatzes gesuchte Bindeglied zwischen Eros und Ethos aufgefunden. Mit etwas spekulativem Eifer könnte es nun auch gelingen, Platos Einsichten auf die medizinische Ebene zu übertragen. Dazu würde es eigentlich genügen, die Idee der Schönheit mit jener der Gesundheit zu ersetzen. Diese steht zweifelsohne

\section{Eros könnte man als eine Art feu sacré verste-} hen, das uns Ärzte und Ärztinnen während des ganzen Berufslebens nie ganz loslassen soll.

ebenfalls dem Guten nahe und ist das ethisch richtige, überall aufzusuchende Ziel jeder medizinischen Aktivität. Eros, das umtriebige, stets bedürftige Mangelwesen, darf uns dabei behilflich sein. Man könnte ihn nämlich als eine Art von innerem Feuer, als mythisches feu sacré verstehen, das uns Ärzte und Ärztinnen nie ganz loslassen soll. Wir brauchen es als steten Antrieb, unser notorisch defizitäres Wissen um die wahre Natur der Gesundheit das ganze Berufsleben hindurch zu vertiefen. Dies eben gerade als Ausdruck des ärztlichen Ethos im Hinblick auf die Bewahrung und Wiederherstellung der Integrität der uns anvertrauten Patienten. 